\title{
Ecological Aspect of Dam Design for Flood Regulation and Sustainable Urban Development
}

\author{
Vladimir Badenko ${ }^{1}$, Nikolai Badenko ${ }^{1}$, Aleksandr Nikonorov ${ }^{1, *}$, Dmitry Molodtsov ${ }^{1}$, \\ Vitaly Terleev ${ }^{1}$, Julia Lednova ${ }^{1}$ and Vladimir Maslikov ${ }^{1}$ \\ ${ }^{1}$ Peter the Great St. Petersburg Polytechnic University, 195251 Polytechnicheskaya str. 29, \\ St. Petersburg, Russia
}

\begin{abstract}
Many floodplains are excluded from urban development because the floods cause considerable damage to people's lives and properties. This requires the development of new approaches to flood management and mitigation for support sustainable urban development. In present study as the measures for mitigation of flash floods, the regulation of river flow by the system of detention reservoirs for flood diversion with dams, which do not need any operation management, are analyzed concerning of Far East region of Russia. The main objective of this paper is to develop a method for analysis how the dam site selection meets the environmental criterion. The method to justify a selection of self-regulated flood dam parameters, primarily a height of a dam and its location on a water stream, providing minimization of impact on the environment have been developed. The result for Selemdzha river basin in Far East monsoon region of Russian Federation is analyzed. The result shows the robustness of the method.
\end{abstract}

\section{Introduction}

Floods are one of the most dangerous natural disasters. Flooding is an issue that affects all countries and each year they cause considerable damage to people's lives and properties. This leads to that many floodplains are excluded from sustainable urban development. Therefore the development of new approaches to flood management and mitigation are required for sustainable urban development. Thus with the Directive 2007/60/EC of the European Parliament and of the Council of 23 October 2007 on the assessment and management of flood risks the strategy changed from Flood Protection to Flood Risk Management $[1,2]$. Furthermore, climate change is likely to increase the frequency of flood events, thus increasing the associated hazard [3]. Therefore, the likelihood of the overuse of land in flood-prone areas and the risk of devastating floods grows with population growth, particularly in urban areas.

One of most dangerous type of flood events is sudden (flash) flood. These phenomena are caused by a specific type of intensive rain (rain storm) over a river basin. As a result, a catastrophic rise of water levels and flows in catchment streams are observed. There are many publications, which are devoted to preparing of appropriate flood-protection measures [4-7]. Some of these measures are detention reservoir for flood diversion with dams, which do not need any operation management and could regulate water level 
automatically [8]. Such types of structural measures for mitigation of flash floods are analyzed in this paper. In addition, it must be pointed out that floods cause the most damage in urban areas, and the main method of researches is modeling [9-11].

The results in [12] based on economic evaluation in trading off between the construction costs and expected value of damage reduction as the benefits have shown that detention dams are the best alternatives of flood mitigation methods. The work [13] shows the possibility of urban flood modelling applications using the high resolution of topographic data that can nowadays be easily acquired. In addition, flood mitigation measures must taking into account that for local authorities achieving sustainable urban development remains one of the most important goals [14, 15]. Therefore, authorities usually choose low impact mitigations as a sustainable solution for urban storm water management [16]. European Union recognizes that member states may face significant challenges in implementing the Flood Directive [17] and solutions are likely to require sustainable flood detention basins [18]. Some comparison of national and local policy tensions in flood risk management have been presented in [19]. The structural measures for flood mitigation are reviewed and compared to each other in [20] according to the type, duration of application, and the return period of the design flood event, how the project measures are integrated into spatial planning that occur. A wetland park in Zhangzhou City, China is taken as an example to show how to apply the concepts and measures of resource saving and environment friendliness [21]

For Russian Federation, the flash floods are a serious problem too [22]. For example, heavy rain falling in Far East areas of Russia, can create floods with runoff about 12-20 $\mathrm{m}^{3} / \mathrm{s}$ per $\mathrm{km}^{2}$ in small river basins.

For comparison, the runoff of melting of snow during the spring flood does not exceed $4 \mathrm{~m}^{3} / \mathrm{s}$ per $\mathrm{km}^{2}$ in the same river basins. An increasing of volume and frequency of extreme precipitation, particularly in areas with a monsoon climate in the Far East of Russia are forecasted by experts [23]. Preliminary evaluation gave the following results: the frequency of floods caused by heavy rains in the Far East will increase by $1.2-1.5$ times. So, if now they are repeated 1 time to 10 - 15 years in the future, they will be repeated with time intervals to $7-12$ years. The number of floods will increase by $45-60 \%$ in rivers of Far East region of Russia that is a big challenge for sustainable urban development in the region [24].

In present study as the measures for mitigation of flash floods, the regulation of river flow by the system of Self-Regulated Flood Dams (SRFD) are analyzed concerning of Far East region of Russia. These dams are distributed on the river network and can save additional water volume from flash floods in temporary detention reservoirs created by SRFD. The selection of the best sites for the SRFD on specific branch of the river network of the river basin is a multicriteria task with economical, ecological, social and technological criteria on the top level of the criteria hierarchical structure $[25,26]$. It should take into account that a modern feature of flood risk management is integration of ecological, economic and social factors in urban flood risk prevention and mitigation. During sustainable urban development risk-reducing measures for flood events can be in conflict with ecosystem functions and complicate upstream/downstream relations. Flood risks are also influenced by processes in the catchment, such as changes in land-use and increases of vulnerable urban areas for example in floodplains [27].

The main objective of this paper is to develop methods for analysis how the site selection of SRFD ("cross-section" or "point" on a river) meets the environmental criterion. Ecological research is the preliminary analysis before final decision [28]. Consideration of all criteria in complex from the beginning is both labor-consuming and financial expensive arrangement, which only complicates the process. The methodological basis of analysis is 
the modeling in GIS environment of hydrological processes in a river basin based on the basin-landscape approach [29] for the selection of modeling objects.

\section{Materials and methods}

The structural measures are usually used for flood mitigation $[8,12,17,20]$. SRFD may be considered as an example of the structural measures. However, this is a special kind of dam with a hole, which in a normal situation does not resist to flows but in ideal situation, SRFD transforms the flash flood into a $10 \%$ probability flood. For this reason, SRFD has minimal impact on the environment. SRFD is used primarily for solving hydrological problems by changing the shape of the catastrophic flood hydrograph, which become smoother. If SRFD is distributed on branches of mainstream of river basin, then resulting hydrograph in a basin control section will have a smooth shape without peaks, which are characteristics of catastrophic floods. Therefore, flood risks for population and sustainable urban development will decrease. The objective of this work is to develop a method to justify a selection of SRFD parameters, primarily a height of a dam and its location on a water stream, providing minimization of SRFD impact on the environment.

Because ecological criterion is in the focus of the research, following tasks were analyzed in this paper:

- $\quad$ selection of appropriate SRFD parameters in specific location for SRFD;

- calculation of duration of flooding time for each ecosystem/landscape for the particular SRFD parameters during flash floods.

Based on the comparison of duration of flooding time for each ecosystem/landscape at the fixed location of the dams with different heights and width of holes at different points on the river, the best SRFD parameters choosing for specific locations can be performed.

During modeling of hydrological process on river basin rainfall-runoff models [31] are used with following equations. For the velocity of surface runoff under assumption that the Manning equation can be used the following equation is used:

$$
v=k_{r} H^{2 / 3} \sqrt{I}
$$

where $k_{r}$ is roughness (according land use), $I$ - is a slope, $H$ is a depth of water at a soil surface. For a pulse inflow, outflow peaks after a time given by the time lag, and then decays exponentially as follow:

$$
Q_{o}=(1-x /(d t / K)) Q_{i} ; x=1-e^{(-d t / K)}
$$

where $Q_{o}$ is outflow, $d t$ - is a time step, $Q_{i}$ is inflow, $K$ is a delay parameter.

As the selection of appropriate dam height is considered for SRFD at current stage of the research a model with virtually unlimited height is used. This approach makes it possible to get a time for landscapes flooding in river basin for all possible values for a dam height with given flood hydrograph. The calculation of the flood volume $V_{s}(t)$ that is accumulated in a reservoir of SRFD at time $t$ is calculated using balance method:

$$
V_{s}(t)=V_{s}(t-1)+\left(Q_{i}(t)-Q_{o}(t)\right) d t
$$

where $Q_{i}(t)$ - inflow to SRFD, $Q_{i}(t)$ - outflow through SRFD, $d t$ - time step.

For modeling in GIS environment raster model is used for a studied basin. The basic raster layers of the GIS database are following:

- $\quad$ landscapes (land use types) - $\{L S\}$;

- Digital Elevation Model (DTM) $-\{D T\}$. 
In these layers, the pixels of the same size are used. The main resulting layer is a raster layer with the attribute - flood time $-\{T f\}$.

Let $X$ is the location of SRFD on the river; $w$ is the width of the SRFD hole, $H d$ - the height of SRFD. In the basin there are $N$ landscapes. For every $j$-th landscape, a critical $T S_{j}$ flooding time, beyond which for the $j$-th landscape will be an environmental hazard, is known. Let $H Y D(t)$ is the hydrograph of specific flood. $H(t)$ is the water level in the SRFD upstream, before flood $H(t)=$ Const. Flooding begins at time $t=0$. At each time step $t$ is computed $H(t)$ :

$$
H(t)=f(X, w, H d,\{D T\}, H Y D(t-1), H(t-1))
$$

On the basis of $H(t)$ can define a set of pixels which are flooded at time $t:\{L S\}_{t}$. Then for each landscape:

$$
\{T f\}_{j}=\sum_{t}\{L S\}_{t}
$$

Then the condition to select the best location for SRFD can be written as:

$$
\sum_{j}\{T f\}_{j} \rightarrow \min ,\{T f\}_{j}<T S_{j}
$$

A method scheme is based on experience of development of a method for estimation of gross hydropower potential in Russia [30]. The scheme of the proposed method and required databases based on [30] are shown in Figure 1.

On the base of the method proposed a comparison of the hydrological situation in the local watershed during a flash flood in natural conditions (without SRFD) and with SRFD is performed by modeling in a GIS environment.

Also it must be pointed out, that it is necessary to begin with the preliminary sites selection for SRFD to except the wide areas, which have high ecological value. Building of the mathematical model begins with the creation of land use GIS database. Knowledge of the ecological value of the determined river floodplain areas, land use regime specifics are necessary for the definition of main parameters, such as flood covered area and critical time duration of flooding. As initial conditions, flood hydrograph and size of hole (nonoperational) should be considered. It is important to notice, that during the single calculation parameters of the hole would be fixed, and then, selecting these parameters, we could determine the required conditions. In addition, it is important, that the flood hydrograph at this stage of the research is hypothetical. However, the method proposed with real flood event hydrograph can be used. For the realistic calculations, every hydrographs for every scenario will be received, but this kind of hydrograph also can take place.

For modeling, raster GIS representation of river basin landscapes is used. The Python language is used for modelling in GIS environment. 


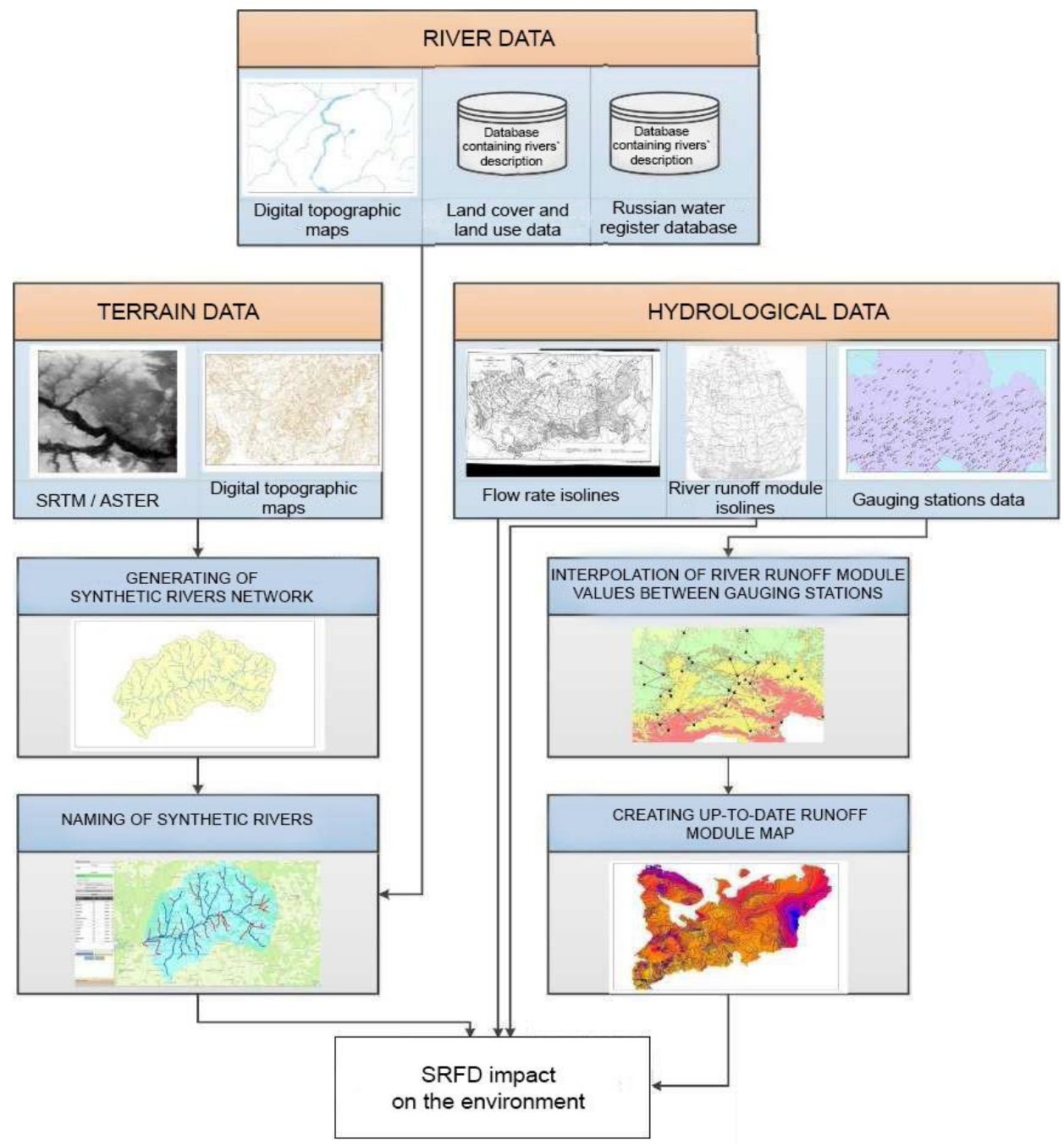

Fig. 1. The scheme of the proposed method.

\section{Results and discussion}

Selemdzha river basin in Far East monsoon region of Russian Federation is considered. Remote sensing data for part of the region analyzed shows in Fig. 2. An urban territory can be found in the middle of the picture. A width floodplain with unstable riverbed can be recognized. This is why the synthetic rivers network using thalweg of digital elevation model are created for modeling. 


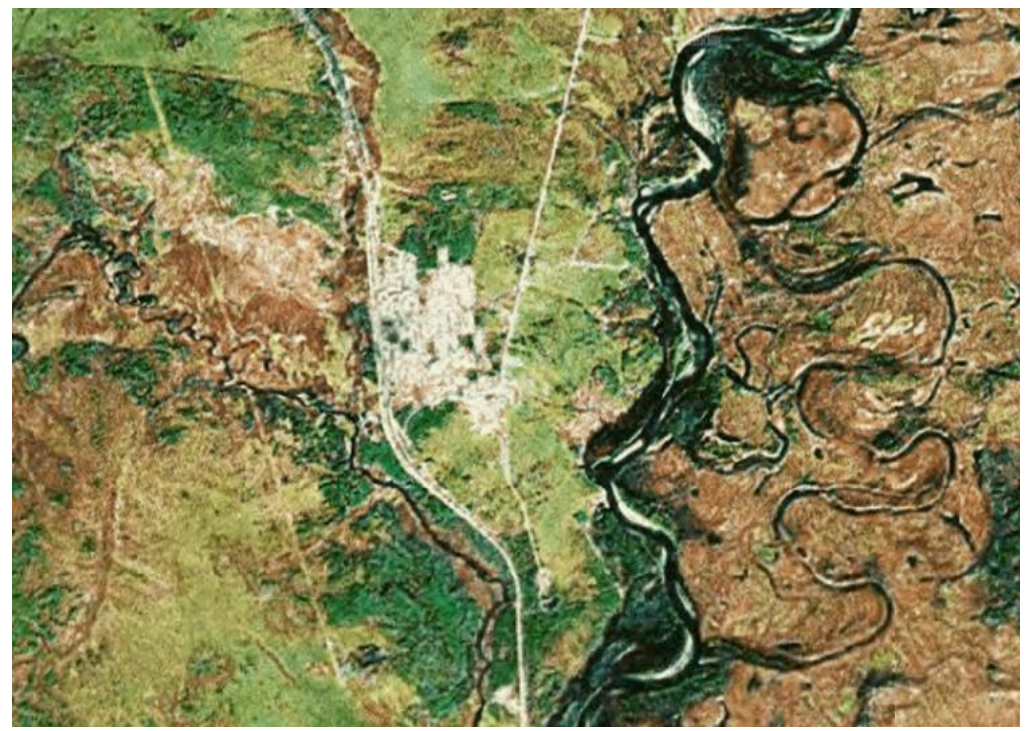

Fig. 2. Remote sensing data for part of the region analyzed.

According to the scheme in Figure 1 and the relations (1) - (6) some scenarios for branches were carried out for the river Selemdzha - Nora basin. The vector and raster layers in GIS database have been created to simulate the hydrological processes on the basin territory. DTM $(\{D T\})$ for the territory was obtained using SRTM dataset.

The results of calculations by the program using the Python language in the form of graphs and thematic GIS maps were obtained. At the current stage of research, in modeling scenarios flood hydrographs of varying triangular shape were used. At the next stage more realistic hygrograph obtained by rainfall/runoff modeling will be use.

Some results for one scenario of flood event in the specific locations shown in Fig.3. A model for the incoming hydrograph with triangular shape is shown in Fig.3A. Also outflow SRFD hydrographs for different SRFD holes ( $\mathrm{w}=3,5$ and 8 meters) is shown in Fig.3A. Fig. 3B shows a thematic GIS map for flooding for the specific locations of SRFD $\left(\{L S\}_{t}\right.$. for using in (5) formula) Flooding time duration for $w=5 m$ is shown with different color. Pixel size for the raster GIS database is 100 meters.

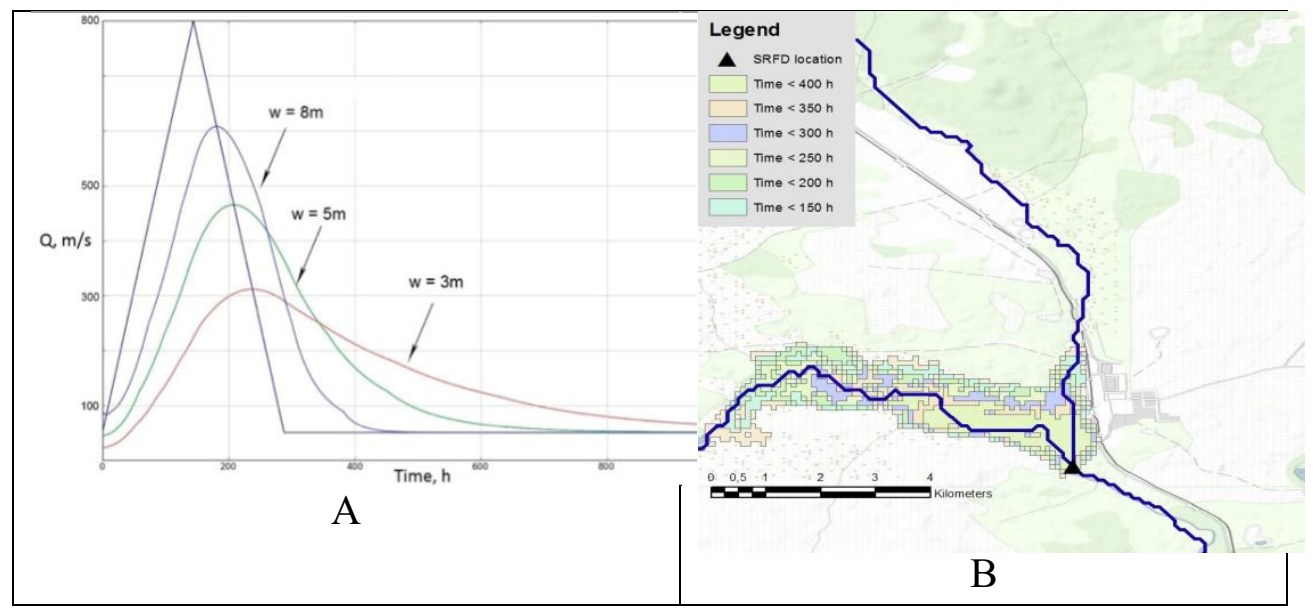

Fig. 3. Results of modelling in GIS environment. 
Raster GIS database layer in Fig.3B was combined with the landscape layer and critical times to fit (6) formula. This allowed a comparison of locations with others and chooses a location that has a minimal impact on the environment.

If ecological management concerning risk-based flood management define as a system approach that assesses and compares the structural and non-structural measures to pursue the best ameliorating effects, than the method proposed can solve some sustainable urban development problem in flood-prone areas taking into account environmental impact [3134]. The method proposed adapts the principles supporting structural measures as diverting water away from urban area to making room for water and save natural landscapes.

\section{Conclusions}

As the measures for mitigation of flash floods, the regulation of river flow by the system of detention reservoirs for flood diversion with dams, which do not need any operation management, are analyzed concerning of Far East region of Russia. The method for analysis how the dam site selection meets the environmental criterion is developed. This method used to justify a selection of self-regulated flood dam parameters, primarily a height of a dam and its location on a water stream, providing minimization of impact on the environment have been developed. The method proposed adapts the principles supporting structural measures as diverting water away from urban area to making room for water and save natural landscapes. The result for Selemdzha river basin in Far East monsoon region of Russian Federation shows the robustness of the method.

\section{Acknowledgements}

The research was supported by Russian Science Foundation (grant \#16-17-00050).

\section{References}

1. C. Butler, N. Pidgeon, Government and Policy, 29, 533-547 (2011)

2. J. Ran, Z. Nedovic-Budic, Computers, Environment and Urban Systems, 57, 68-79 (2016)

3. L. Yao, W. Wei, L. Chen, Ecological Indicators 60, 893-905 (2016)

4. N. Arefiev, V. Badenko, A. Nikonorov, V. Terleev, Y. Volkova, Procedia Engineering, 117, 20-25 (2015)

5. A. Nikonorov, S. Pavlov, V. Terleev, N. Arefiev, V. Badenko, Y. Volkova, Procedia Engineering, 117, 258-263 (2015)

6. K.M. Debusk, T.M. Wynn, Journal of Environmental Engineering, 137, 800-808 (2011)

7. L. Ahiablame, R. Shakya, Journal of Environmental Management ,171, 81-91 (2016)

8. D. Nijssen, A. Schumann, M. Pahlow, B. Klein, Natural Hazards and Earth System Science, 9, 1349-1363 (2009)

9. V.V. Elistratov, V.I. Maslikov, G.I. Sidorenko, Power Technology and Engineering, 49, 6-10 (2015)

10. A.H. Thieken, H. Kreibich, M. Müller, B. Merz, Hydrological Sciences Journal, 52, 1016-1037 (2007)

11. M. Guan, N. Sillanpää, H. Koivusalo, Hydrological Processes, 29, 2880-2894 (2015)

12. A. Heidari, Natural Hazards and Earth System Science, 9, 61-75 (2009)

13. J. Leandro, A. Schumann, A. Pfister, Journal of Hydrology, 535, 356-365 (2016)

14. A.M. Hassan, H. Lee, Land Use Policy, 48, 199-212 (2015) 
15. M.P. Fedorov, V.V. Elistratov, V.I. Maslikov, G.I. Sidorenko, A.N. Chusov, V.P. Atrashenok, D.V. Molodtsov, A.S. Savvichev, A.V. Zinchenko, Power Technology and Engineering, 49, 33-39 (2015)

16. H. Qin, Z. Li, G. Fu, Journal of Environmental Management, 129, 577-585 (2013)

17. Z.W. Kundzewicz, N. Lugeri, R. Dankers, Y. Hirabayashi, P. Döll, I. Pińskwar, T. Dysarz, S. Hochrainer, P. Matczak, Mitigation and Adaptation Strategies for Global Change, 15, 641-656 (2010)

18. M. Scholz, Q. Yang, Landscape and Urban Planning, 98, 190-199 (2010)

19. S. Beucher, Environmental Hazards, 8, 101-116 (2009)

20. A. Kryžanowski, M. Brilly, S., Rusjan, S. Schnabl, Natural Hazards and Earth System Sciences, 14, 135-142 (2014)

21. L. Qiao, M. Li, Y. Zhang, X. Zhao, Nature Environment and Pollution Technology, 15, 221-226 (2016)

22. A.B. Avakyan, M.N. Istomina, Power Technology and Engineering, 35, 89-93 (2001)

23. P.C.B. Milly, R.T. Wetherald, K.A. Dunne, T.L. Delworth, Nature, 415, 514-517 (2002)

24. S.G. Dobrovolskii, M.N. Istomina, Water Resources, 36, 491-506 (2009)

25. N. Arefiev, V. Terleev, V. Badenko, Procedia Engineering, 117, 39-44 (2015)

26. D. Kurtener, V. Badenko, Journal of the Brazilian Computer Society, 6, 26-32 (2000)

27. L. Nyberg, M. Evers, M. Dahlström, A. Pettersson, Aquatic Ecosystem Health and Management, 17, 331-340 (2014)

28. V. Bauni, F. Schivo, V. Capmourteres, M. Homberg, Remote Sensing Applications: Society and Environment, 1, 50-60 (2015)

29. N.V. Aref'ev, V.L. Badenko, G.K. Osipov, Power Technology and Engineering, 32, 660-663 (1998)

30. N. Arefiev, O. Nikonova, N. Badenko, T. Ivanov, V. Oleshko, "ENVIRONMENT. TECHNOLOGY. RESOURCES" Proceedings of the 10th International Scientific and Practical Conference, 41-50 (2015)

31. M.P. Fedorov, A.G. Bogolyubov, V.I. Maslikov, Environmental safety of power plants using renewable sources of energy, Hydrotechnical Construction, 29, 353-357 (1995)

32. V. Terleev, A. Nikonorov, V. Badenko, I. Guseva, Y. Volkova, O. Skvortsova, S. Pavlov, W. Mirschel, Advances in Civil Engineering, 2016, 7 (2016)

33. O. Skvortsova, A. Dashkina, E. Petrovskaia, V. Terleev, A. Nikonorov, V. Badenko, Y. Volkova, S. Pavlov, MATEC Web of Conferences, 53, 7 (2016)

34. V. Terleev, E. Petrovskaia, N. Sokolova, A. Dashkina, I. Guseva, V. Badenko, Y. Volkova, O. Skvortsova, O. Nikonova, S. Pavlov, A. Nikonorov, V. Garmanov, W. Mirschel, MATEC Web of Conferences ,53, 6 (2016) 